\title{
IMPLEMENTASI TOTAL QUALITY MANAGEMENT TERHADAP BUDAYA KUALITAS
}

\author{
Robert Fransiska \\ Email : robert_fransiska@gmail.com
}

STIE Palangka Raya

\begin{abstract}
Total QualityManagement (TQM) is a new paradigm in running a business with the goal to maximize organizational competiveness through focuses on consumer satisfaction, all employee engagement, and sustainable improvement on quality of products, services, human, process and organizational environment.

This research aims to determine the amount of effects by variables in the implementation of Total QualityManagementconsisting of:focuses on consumers, sustainable improvement, management commitment, training, employee empowering, performance comparison, and use of simultaneous statistic equipment on quality culture.

The research method uses type of explanatoryresearch with quantitative approach because it tries to describe inter-variable correlation through hypothesis testing, meanwhile in general, the data used are in the form of number calculated by statistic test.

Results of the research are (a) Simultaneously the variables in the implementation of TotalQuality Managementare able to describe the effects on the quality culture variable by $63,5 \%$, meanwhile the remaining is described or influenced by other independent variables beyond the research model equation. Inter-variable correlation in the implementation of Total Quality Management on the quality culture is quite strong (b) There are significant effects between variables in the implementation of Total QualityManagementconsisting of focuses on employee, management commitment, training, employee empowering, and use of statistic devices partially on quality culture variable, meanwhile the sustainable improvement and performance comparison do not influence significantly on quality culture variable. Thus, the second hypothesis of this research is rejected (c) The training variable provides dominant effects on the quality culture variable. Thus the third hypothesis of this research is rejected.
\end{abstract}

Keywords: TQM, performance, quality culture 


\section{PENDAHULUAN}

Total Quality Management (TQM) adalah sistem pengendalian mutu yang didasari pada filosofiadalah pemenuhan kebutuhan pelanggan dengan sebaik-baiknya. Kebutuhan pelanggan tersebut harus melebihi keinginan pemakai jasa/produk. Persaingan pasar global dewasa ini, tuntutan konsumen atas peningkatan kualitas produk dan jasa bertambah. Terjadi pula peningkatan penawaran produk dan jasa dengan harga lebih bersaing dari Negara dengan biaya tenaga kerja rendah (Dale,2003)

Satu hal yang sangat berarti dalam meningkatkan kinerja menghadapi tantangan persaingan tersebut adalah melalui perbaikan berkelanjutan pada aktivitas bisnis yang terfokus pada konsumen, meliputi keseluruhan organisasi dan penekanan pada fleksibilitas dan kualitas (Krajewski, Lee, dan Ritzman, 1999).

Hasil upaya-upaya tersebut menjadikan organisasi mampu merespon permintaan pasar atas kualitas produk, jasa dan proses yang telah dikembangkan secara meluas selama dua decade terakhir.
Tujuan penelitian (1) Untuk mengetahui seberapa besar pengaruh variabel-variabel dalam implementasi Total Quality Management meliputi (a) focus pada konsumen (b) perbaikan berkelanjutan, komitmen manajemen (c) pelatihan, pemberdayaan karyawan, perbandingan kinerja (d) penggunaan metode statistik secara simultan terhadap budaya kualitas Maspion Group.

\section{TINJAUAN TEORITIS}

Konsep yang relevan dan terkait dengan penelitian ini secara garis besar dikelompokkan menjadi tiga bagian, yaitu:penelitian yang menyangkut faktor-faktor yang mempengaruhi keberhasilan implementasi TQM, penelitian tentang pengaruh implementasi TQM terhadap kinerja individu maupun organisasi, dan penelitian tentang implementasi TQM dikaitkan dengan budaya organisasi.

Penelitian yang menyangkut faktor-faktor kritis yang mempengaruhi keberhasilan implementasi TQM diantaranya telah dilakukan oleh Dayton (2003). Penelitian ini menyimpulkan bahwa faktor kritis yang telah 
diidentifikasi dalam penelitian di Eropa tahun 1996 juga sebagai faktor kritis implentasi TQM di Amerika Serikat. Sedangkan faktor TQM yang paling penting adalah manajemen kualitas strategis yang mengutamakan komitmen jangka panjang dan dukungan manajemen puncak agar implementasi TQM berhasil.

Penelitian sejenis juga telah dilakukan oleh Baidoun (2003) yang telah melakukan studi empiris tentang faktor-faktor kritis TQM pada organisasi- organisasi di Palestina. Dari 19 faktor TQM yang diduga sebagai faktor kritis yang menentukan keberhasilan implementasi TQM kemudian distratifikasi ke dalam tiga kelompok menurut tingkat pengaruhnya: faktor-faktor yang penting bagi keberhasilan TQM yang dipersepsikan oleh seluruh responden berdampak pada keberhasilan implementasi TQM (9 faktor); faktorfaktor yang penting bagi keberhasilan TQM yang dipersepsikan oleh beberapa responden saja berdampak pada keberhasilan implementasi TQM (8 faktor); dan faktor-faktor berdampak sangat rendah proses implementasi TQM (2 faktor). Penelitian ini menyimpulkan bahwa faktor kritis yang telah distratifikasi dalam kelompok pertama, dikenal dalam literatur TQM sebagai komponen fundamental yang diutamakan dalam tahapan awal proses implementasi. Kesimpulan ini menempatkan komitmen manajemen puncak sebagai faktor pertama yang menentukan keberhasilan implementasi TQM.

Metri (2005) juga telah melakukan analisis komprehensif dan pengujian kerangka kerja dan literature TQM yang ada menghasilkan sepuluh faktor (Critical Success Factor/CSFs) yang menentukan keberhasilan implementasi TQM bagi perusahaan konstruksi. Hasil analisis ini juga menempatkan komitmen manajemen puncak sebagai prioritas yang pertama.

Sedangkan penelitian tentang faktor-faktor yang berpengaruh terhadap keberhasilan implementasi TQM disuatu organisasi telah dilakukan oleh Munizu (2003) pada karyawan produksi Pabrik Karung (PK) Rosella Baru PTPN XI(Persero) Surabaya. Hasil Penelitian tersebut menyimpulkan bahwa: (1) Faktor- faktor yang terdiri dari iklim yang mendukung, komitmen manajemen puncak, pemilihan sasaran, informasi dan komunikasi, kesukarelaan, pelatihan, tumbuh dengan 
bertahap tapi mantap, selalu terbuka dan positif secar aserentak maupun secara parsial mempunyai pengaruh terhadap keberhasilan pelaksanaan GKM (2) Faktor komitmen manajemen puncak mempunyai pengaruh yang sangat signifikan terhadap keberhasilan pelaksanaan Gugus Kendali Mutu (GKM).

Sejalan dengan penelitian sebelumnya, Wahyudi (2004) juga telah melakukan analisis terhadap faktor yang berpengaruh dalam Implementasi TQM di PT. Pulogadung Pawitra Laksana menggunakan model perubahan Pettigrew dan Whipp (1991) yang terdiri dari 3 dimensi: konteks, konten dan proses. Hasil penelitian tersebut menyimpulkan bahwa variabel yang mendukung proses implementasi TQM yaitu: kerjasama, kepemimpinan, manajemenproses, komitmen, komunikasi dan perubahan.

Penelitian tentang pengaruh implementasi TQM terhadap kinerja organisasi diantararanya dilakukan oleh HuarngdanYao (2002) yang telah melakukan analisis faktor menghasilkan enam faktor kritis implementasi TQM yaitu: 2 faktor filosofis TQM (pemberdayaan karyawan dan dukungan eksekutif puncak) dan 4 faktor piranti
TQM (pelatihan, penggunaan metode statistik, perbandingan kinerja, dan kerja sama dengan pemasok). Hasil penelitian tersebut menyimpulkan bahwa filosofi TQM maupun piranti TQM secara parsial tidak berpengaruh pada pengurangan biaya, tetapi integrasi filosofi dengan piranti TQM berpengaruh secara signifikan terhadap pengurangan biaya maupun kinerja bisnis.

Penelitian yang lebih terfokus pada aspek sumberdaya manusia diantaranya dilakukan oleh: Bey, Nimran,dan Kertahadi (1998) yang mengkaitkan implementasi TQM dengan motivasi kerja karyawan PT.Semen GresikPersero. Hasil penelitian menyimpulkan bahwa secara serempak keenam variabel implementasi TQM berpengaruh signifikan terhadap variabel motivasi kerja. Sedangkan secara parsial variabel menghormati martabat manusia dan mengutamakan kepuasan pelanggan berpengaruh dominan terhadap motivasi kerja.

Boselie dan Wiele (2001) telah meneliti persepsi karyawan Ernst\&young (DutchCompany) terhadap Human Resources Management and Total Quality Management (HRM/TQM) terhadap 
kepuasan dan minat untuk pindah kerja. Penelitian tersebut menghasilkan beberapa kesimpulan, yaitu: persepsi positif karyawan atas konsep HRM/TQM mengakibatkan tingkat kepuasan yang tinggi dan menurunkan minat untuk pindah kerja; Tingkat kepuasan yang tinggi mempunyai korelasi dengan tingkat yang rendah atas minat untuk keluar dari organisasi; Kerjasama antar unit, kepemimpinan, dan gaji menunjukkan korelasi positif yang sangat signifikan pada kepuasan karyawan; Sebagian besar variabel menunjukkan hubungan yang negative dan signifikan pada minat untuk pindah, walaupun tidak terlalu kuat. Kepemimpinan, dan pemahaman atas sasaran dan tujuan. Menunjukkan hubungan negative yang relative kuat dengan minat untuk pindah.

Hasil penelitian Laily (2003) yang dilakukan di PT.Petrokimia Gresik-Persero menyimpulkan bahwa secara serentak sikap manajer menengah terhadap faktor kritis TQM berpengaruh terhadap kinerja manajerial. Sedangkan analisis dengan menggunakan uji beda menunjukkan tidak ada perbedaan sikap antara manajer menengah operasional dan non operasional terhadap faktor kritis TQM.
Penelitian sejenis juga dilakukan oleh Sularso dan Murdijanto (2004). Hasil penelitian menunjukkan bahwa variabel: peran karyawan, peran pimpinan, hubungan pimpinan dan karyawan, aspek organisasi dan aspek lingkungan berpengaruh secara nyata terhadap peningkatan: kemampuan teoritis, kemampuan teknis, kemampuan konseptual, kemampuan moral, ketrampilan teknis, dan kualitas sumberdaya manusia.

Berbeda dengan penelitianpenelitian sebelumnya, penelitian Terziovski, Samson, dan Dow (2003) yang telah menganalisis secara acak perusahaan manufaktur di Australia dan Selandia baru menghasilkan temuan utama bahwa sertifikasi ISO 9000 tidak menunjukkan pengaruh positif yang signifikan pada kinerja organisasi, juga tidak ada perbedaan kinerja organisasi antara perusahaan yang menerapkan TQM dengan yang tidak menerapkan TQM. Ini mendukung pandangan bahwa sertifikasi ISO 9000 mempunyai sedikit atau tidak menjelaskan kekuatan kinerja organisasi.

Hasil berbeda juga ditemukan pada hasil penelitian Prajogo dan Brown (2004) yang juga dilakukan pada perusahaan-perusahaan di Australia. 
Penelitian menyimpulkan bahwa perusahaan yang mengadopsi program TQM formal dalam hal praktek-praktek TQM lebih unggul daripada yang tidak menerapkan program TQM. Temuan juga menunjukkan adanya pengaruh yang kuat antara praktek TQM dan kinerja kualitas tetapi tidak ada perbedaan kinerja kualitas yang signifikan antara organisasi yang menerapkan program TQM secara formal dengan organisasi yang mengadopsi praktek TQM secara non formal. Ini menunjukkan bahwa adopsi praktek kualitas adalah hal yang lebih penting daripada sekedar program formal.

Penelitian tentang implementasi TQM yang dikaitkan dengan budaya organisasi antara lain telah dilakukan oleh Gore (1999) pada sejumlah organisasi di Amerika Serikat. Hasil penelitian tersebu tmenyimpulkan bahwa: TQM efektif mengembangkan elemen budaya kualitas dan budaya tersebutmenunjang keberhasilan perbaikan proses, sebaliknya praktek reengineering tidak mengembangkan budaya pendukung dan kurang menunjang keberhasilan perbaikan proses; perbaikan prosesakan lebih berhasil dengan adanya elemen budayakualitas.

Sayeh, Dani, Swain (2005) juga telah mengadakan penelitian terhadap dua kelompok organisasi di Libya. Hasil penelitian tersebut menyimpulkan bahwa: pada kelompok organisasi berlatarbelakang beragam, gaya manajemen yang dominan saat ini adalah power, sedangkan yang disukai adalah Achievement, sedangkan pada kelompok organisasi bersertifikat ISO gaya manajemen dominan saat ini adalah Role, dan yang lebih disukai adalah Achievement; Manajer industry di Lybia memilih gaya manajemen Achievement dan atau Support yang mendukung efektivitas implementasi TQM.

Parncharoen, Girardi, dan Entrekin (2005) telah membandingkan dampak nilai-nilai budaya pada keberhasilan implementasi TQM di Australia dengan di Thailand. Hasil penelitian tersebut menyimpulkan bahwa: desainorganisasi mempunyai pengaruh yang signifikan terhadap keberhasilan TQM; perbedaan signifikan antara model desain organisasi di Australia dan Thailand pada keberhasilan TQM lebih karena perbedaan budaya, menunjukkan fakta 
bahwa budaya mempengaruhi orangorang berfikir dan berperilaku; perbedaan substansial kedua model tersebut adalah pengaruh sentralisasi pada keberhasilan TQM lebih nyata di Australia daripada di Thailand, sedangkan pengaruh formalisasi dan sistem pengupahan lebih nyata di Thailand daripada di Australia.

Berbedadenganpenelitiansebelu mnya, penelitian yang telah dilakukan oleh Jabnon dan Sedrani (2005) menambahkan variabel kinerja organisasi sebagai indikator keberhasilan implementasi TQM, selain variabel TQM dan budaya organisasi. Penelitian ini diawali dengan analisis faktor terhadap praktek TQM dan budaya organisasi menghasilkan empat dimensi TQMdan lima dimensi budaya. Hasil penelitian tersebut menyimpulkan bahwa: focus pada konsumen dan perbaikan berkelanjutan mempunyai koefisien korelasi yang paling tinggi terhadap keseluruhan kinerja; kedua dimensi TQM tersebut dan dimensi budaya (orientasi pada manusia) mempunyai efek kombinasi dan mempunyai kontribusi dalam menurunkan komplain konsumen, meningkatkan reliabilitas, dan profitabilitas; sedangkan focus pada konsumen dan perbaikan berkelanjutan dan interaksinya dengan dimensi budaya (kemampuan daya saing) mempunyai kontibusi dalam meningkatkan pangsa pasar.

$$
\text { Penelitian yang lebih }
$$

komprehesif juga telah dilakukan oleh Srismith (2005) yang mengkaitkan budaya kualitas sebagai indikator keberhasilan implementasi TQM dengan praktek komunikasi terpadu. Hasil penelitian tersebut menyimpulkan bahwa:ada interaksi positif antara budaya dominan 'Clan', prinsip-prinsip TQM, sikap dan perilaku komunikasi; Secara umum organisasi lebih memilih Supportive Communication Climate, kecuali leveloperasional memilih defensive Communication Climate, karena merasa nyaman dengan hierarki dan formalisasi organisasi; Tiga prinsip TQM: customer focus, continuous improvement, common vision berpengaruh tidak langsung terhadap praktek komunikasi. Empat prinsip TQM: process focus, leadership support problem solving \& teamwork, empowerment berpengaruh langsung terhadap praktek komunikasi.

Kajian teoritis dan empiris menunjukkan bahwa ada beberapa persamaan maupun perbedaan diantara 
faktor-faktor kritis TQM yang mempengaruhi keberhasilan implementasi TQM yang telah dikemukakan oleh beberapa pakar maupun peneliti terdahulu, tetapi secara substansial dapat ditarik benang merahnya. Penggunaan faktor-faktor kritis TQM dalam penelitian-penelitian tersebut juga menunjukkan pengaruh yang beragam terhadap kinerja individu maupun organisasi.

Faktor-faktor kritis TQM yang dikemukakan oleh Huarng dan Yao (2002) lebih komprehensif dibandingkan dengan yang lain karena mereka memadukan keseimbangan antara softand hard side (Jabnon dan Sedrani, 2005:9). Oleh karena itu penelitian ini terutama menggunakan faktor-faktor kritis tersebut mengingat lokasi penelitian sama-sama negara di kawasan Asia (Taiwan), sedangkan penelitian sejenis yang dilakukan di Indonesia masih terbatas. Faktor-faktor kritis kemudian dimodifikasi dengan model penelitian yang telah dilakukan oleh Jabnon dan Sedrani (2005) dan Srismith (2005), selain karena mereka menambahkan variabel dimensi budaya, penelitian ini juga dilakukan di kawasan Asia (United Arab Emirates/UAE dan Thailand).
Modifikasi model Huarng dan Yao (2002), Jabnoun dan Sedrani (2005), dan Srismith (2005) tersebut menghasilkan tujuh variabel implementasi TQM yang digunakan dalam penelitian ini, yaitu: focus pada konsumen, perbaikan berkelanjutan, komitmen manajemen, pelatihan, pemberdayaan karyawan, perbandingan kinerja, dan penggunaan piranti statistik.

Dari kajian teoritis dan empiris sebelumnya juga diketahui bahwa diantara ke tujuh variabel implementasi TQM tersebut secara umum yang berpengaruh dominan terhadap keberhasilan implementasi TQM adalah variabel komitmen manajemen sebagaimana pendapat beberapa pakar kualitas, antara lain: Hashmi (2004), Curkovic dan Landeros (2000:67), dan Paskard (1995), juga didukung hasil penelitian yang dilakukan oleh: Dayton (2003), Baidoun (2003), Munizu (2003), dan Metri (2005). Oleh karena itu, penelitian ini juga menggunakan hipotesabahwa komitmen manajemen mempunyai pengaruh yang dominan terhadap budaya kualitas.

Penelitian terdahulu yang mengkaitkan implementasi TQM dengan fenomena budaya organisasi 
secara umum masih terbatas pada studi tentang pengaruh budaya organisasi terhadap keberhasilan maupun kegagalan implementasi TQM, bukan sebaliknya apakah implementasi TQM mampu mempengaruhi, mengubah bahkan membentuk budaya organisasi sebagaimana pendapat beberapa pakar kualitas. Pendekatan budaya organisasi yang dilakukan juga masih terbatas pada level pertama (Artefacts and Creation) dan level kedua (Values and Beliefs).

Tinjauan teoritis diketahui bahwa implementasi TQM dapat merubah orientasi budaya suatu organisasi menuju budaya kualitas yang merupakan salah satu indikator keberhasilan implementasi TQM dan pada akhirnya dapat meningkatkan daya saing organisasi Cortada, (1993) Goetsch dan Davis dalam Tjiptono dan Diana, (2003) Hardjosoedarmo (2005) dan Metri, 2005) Dilain pihak menurut Hardjosoedarmo (2004), dalam hal kualitas, apabila organisasi hanya mencapai wujud nyata saja (level pertama), maka yang diperoleh hanyalah "cosmetic quality" saja. Untuk mencapai internalisasi kualitas maka organisasi perlu bertumpu pada level ketiga yaitu asumsi dasar (Basic Assumption)..

Oleh karena itu,terdapat perbedaan mendasar antara penelitian ini dengan penelitian-penelitian sebelumnya, yaitu: meneliti pengaruh implementasi TQM terhadap budaya kualitas (bukan sebaliknya), dan menggunakan model budaya menurut Kujala dan Ullrank (2004) yang diadopsi dari level budaya organisasi menurut Schein, karena lebih komprehensif, terbaru, dan terfokus pada budaya kualitas (TQM basic assumptions and corevalues).

\section{METODE PENELITIAN}

\section{Pendekatan Penelitian}

Penelitian tentang pengaruh Implementasi Total Quality Management terhadap budaya kualitas ini termasuk jenis penelitian explanatory dengan pendekatan kuantitatif karena berusaha menjelaskan hubungan antara variabel- variabel melalui pengujian hipotesis, sedangkan data yang digunakan secara umum berupa angka-angka yang dihitung melalui uji statistik. 


\section{InstrumenPenelitian}

Penelitian ini menggunakan instrument kuesioner yang didalamnya terdapat sejumlah pernyataan tertulis yang digunakan untuk memperoleh tanggapan dan informasi dari responden.

\section{Analisis Regresi Berganda}

Penelitian ini juga menggunakan analisis inferensial untuk menguji pengaruh antara variabel-variabel dalam implementasi TQM terhadap variabel budaya kualitas, dan menguji hipotesis yang telah dirumuskan. Model analisis yang digunakan adalah regresi linier berganda dengan menggunakan bantuan perangkat lunak komputer (software) program SPSS (Statistical Product and ServiceSolutions) versi 24.0 for Windows, dengan rumus sebagai berikut: $Y=\beta 0+\beta_{1} X_{1}+\beta_{2} X_{2}+\beta_{3} X_{3}+\beta_{4} X_{4}$ $+\beta 5 \mathrm{X}_{5}+\beta_{6} \mathrm{X}_{6}+\beta_{7} \mathrm{X}_{7}+\varepsilon$

Keterangan:

$$
\begin{array}{ll}
\mathrm{Y} & =\text { Budayakualitas } \\
\beta 0 & =\text { Konstanta(intersep) } \\
\beta 1 . . \beta 7 & =\text { Koefisienregresi } \\
\mathrm{X} 1 & =\text { Fokuspadakonsumen } \\
\mathrm{X} 2 & =\text { Perbaikanberkelanjutan } \\
\mathrm{X} 3 & =\text { Komitmenmanajemen } \\
\mathrm{X} 4 & =\text { Pelatihan } \\
\mathrm{X} 5 & =\text { Pemberdayaankaryawan } \\
\mathrm{X} 6 & =\text { Perbandingankinerja } \\
\mathrm{X} 7 & =\text { Penggunaanpiranti } \\
\varepsilon & =\text { Kesalahanpengganggu }
\end{array}
$$

\section{HASIL PENELITIAN}

\section{Pengaruh Simultan}

Hasil pengujian hipotesis pertama menunjukkan bahwa variabelvariabel dalam implementasi Total Quality Management (TQM) secara simultan mempunyai pengaruh yang signifikan terhadap budaya kualitas. Hal ini dapat diinterpretasikan bahwa implementasi TQM yang didokumentasikan dalam klausulklausul ISO9001:2000 dan diterapkan kurang lebih selama sepuluh tahundi Maspion Group telah mampu membentukdanmerubah orientasi budaya organisasi menjadi budaya kualitas.

Kedelapan prinsip TQM yang tertera dalam klausul-klausul ISO 9001:2000 tersebut diantaranya adalah: focus organisasi pada konsumen, kepemimpinan, keterlibatan karyawan, pendekatan proses, pendekatan sistem pada manajemen, perbaikan berkelanjutan, pendekatan factual dalam pengambilan keputusan, kemitraan yang saling menguntungkan.

Hasil penelitian tersebut mendukung pendapat beberapa pakar kualitas, diantaranya: implementasi TQM dapat merubah orientasi budaya suatu organisasi menuju budaya 
kualitas (Cortada, 1993; Goetsch dan

Davis dalam Tjiptono, 2003; dan

Hardjosoedarmo, 2005); budaya kualitas

dipertimbangkan sebagai salah satu hal yang terpenting sebagai indikator keberhasilan implementasi TQM (Metri, 2005); dan studi empiris: TQM efektif mengembangkan elemen budaya kualitas dan budaya tersebut menunjang keberhasilan perbaikan proses (Gore, 1999); integrasi filosofi dengan piranti TQM berpengaruh signifikan terhadap kinerja bisnis (Huarng dan Yao, 2002). Menurut teori Schein (1985), budaya dibangun dalam tiga level. Level pertama adalah wujud nyata yang meliputi kegiatan dan kejadian sebagai hasil pemikiran (Artefactsand Creation), Level kedua adalah nilainilai dan keyakinan (Values and Beleifs), dan level ketiga adalah asumsi dasar yang merupakan pandangan terhadap masalah (BasicAssumption). Selanjutnya menurut Hardjosoedarmo (2004), dalam hal kualitas, apabila organisasi hanya atau baru mencapai wujud nyata saja (levelpertama), maka yang diperoleh hanyalah "cosmeticquality"saja.Untuk mencapai internalisasi kualitas maka organisasi perlu bertumpu pada asumsi dasar (BasicAssumption) tentang perlunya kualitas demi kelangsungan hidup dan perkembangan kehidupannya yang dikenal dengan budaya kualitas (Kekale,1999; Kujala dan Ullrank, 2004).

Nilai rata-rata setiap variabel bebas: focus pada konsumen, perbaikan berkelanjutan, komitmen manajemen, pelatihan, pemberdayaan karyawan, perbandingan kinerja,dan penggunaan piranti statistik,danvariabel terikat: budaya kualitas yang cenderung tinggi pada tabel5.22, membuktikan bahwa aktivitas implementasi TQM cukup tinggi dan secara simultan mampu membangun budaya kualitas yang tinggi pula.

\section{Pengaruh Persial}

Nilai rata-rata variabel komitmen manajemen yang tertinggi $(4,49)$ dan nilai rata-rata variabel pemberdayaan karyawan yang terendah (3,73), menunjukkan bahwa komitmen manajemen merupakan aktivitas yang relative paling menonjol dan pemberdayaan karyawan merupakan aktivitas yang kurang menonjol jika dibandingkan dengan aktivitas yang lain pada implementasi TQM.

Hasil pengujian hipotesis kedua menunjukkan bahwa secara parsial 
hanya variabel: focus pada konsumen, komitmen manajemen, pelatihan, pemberdayaan karyawan, dan penggunaan piranti statistic yang berpengaruh signifikan terhadap budaya kualitas, sedangkan variabel lainnya tidak berpengaruh signifikan terhadap budaya kualitas. Hasil penelitian ini mendukung penelitian sebelumnya, bahwa: filosofi TQM dan piranti TQM secara parsial tidak berpengaruh signifikan terhadap kinerja bisnis (Huarng dan Yao, 2002); tidak semua variabel-variabel dalam implementasi TQM mempunyai korelasi yang signifikan terhadap dimensi budaya organisasi (Jabnoun dan Sedrani, 2005).

\section{PenggunaanMetodeStatistik}

Variabel penggunaan metode statistic mempunyai pengaruh positif yang signifikan terhadap variabel budaya kualitas. Hal ini membuktikan bahwa penggunaan piranti statistic merupakan variabel yang mempengaruhi terbentuk- nya budaya kualitas.

Hasil penelitian tersebut mendukung pendapat pakar kualitas, bahwa penggunaan piranti statistic merupakan salah satu elemen kunci keberhasilan implementasi TQM
(Krajewski, Lee, dan Ritzman, 1999; Hashmi, 2004). Menurut Dale (2003), penggunaan metode statistic sangat berarti dalam membantu proses perbaikan berkelanjutan, karyawan memanfaatkan metode statistik sebagai bentuk keterlibatan dan kontribusinya, menjadikan kesadaran karyawan terhadap kualitas meningkat, prilaku dan sikap karyawanpun berubah. Selanjutnya Lawson (2004) berpendapat: apa yang diukur, seberapa sering, dan bagaimana informasi tersebut digunakan dan dikomunikasikan, semuanya akan mempengaruhi terbentuknya budaya kualitas.

Beberapa metode statistic yang banyak digunakan oleh perusahaan dalam mengendalikan dan memperbaiki aktivitas perusahaan yang berkaitan dengan semua aspek kualitas diantaranya adalah: sumbangsaran (brainstorming), checklists, diagrampareto, diagram tulang ikan (fishbonediagram), flowchart, controlchart, scatterdiagram, dan histogram.

Penggunaan metode statistic oleh perusahan terbukti telah mampu menekan tingkat kerusakan produk hingga $0,5 \%$ dan meningkatkan 
efisiensi produksi secara keseluruhan hingga 96\%. Penggunaan piranti statistik tersebut juga efektif membangun budaya kualitas.Tanggapan terhadap variabel penggunaan piranti statistic sebesar 4,15, menunjukkan perusahaan telah menggunakan atau memanfaatkan metode statistik,meskipun tidak semua. Tanggapan atas pernyataan` Perusahaan selalu memanfaatkan teknik statistic untuk mengurangi penyimpangan proses kerja' (X72) yang tertinggi $(4,19)$ berarti teknik statistic telah banyak dimanfaatkan untuk mengurangi penyimpangan proses kerja. Sedangkan tanggapan atas pernyataan'Semua peralatan dan proses kerja berlangsung dibawah kendali statistic (StatisticProcessing control)' (X71) yang terendah $(4,12)$ menunjukkan bahwa belum semua peralatan dan proses kerja berlangsung dibawah kendali statistik. Oleh karena itu, pemanfaatan metode dan piranti statistic hendaknya lebih ditingkatkan secara efektif pada keseluruhan peralatan dan proses kerja, karena dapat meningkatkan budaya kualitas di perusahaan.

\section{Pengaruh Dominan}

Hasil penelitian juga menunjukkan bahwa jika dibandingkan dengan variabel- variabel bebas yang lain, variabel pelatihan mempunyai pengaruh yang dominan terhadap variabel budaya kualitas. Hasil penelitian tersebut menolak atau bertentangan dengan pendapat Paskard (1995), Curkovic dan Landeros (2000), dan Hashmi (200), yang menyatakan variabel komitmen manajemen terhadap kualitasdan kepemimpinan merupakan variabel yang paling dominan menentukan keberhasilan implementasi TQM. MenurutLawson (2004) dalam perspektif sistem kualitas, manajemen puncak mempunyai pengaruh yang paling signifikan terhadap budaya kualitas. Apa yang mereka katakana dan lakukan (atau tidak dilakukan) maupun dukungan akan direfleksikan dalam organisasi. Manajemen puncak mendefinisikan idealismenya kedalam misi,visi,nilai-nilai dan kebijakan, secara keseluruhan menjadi referensi bagi karyawan sebagai asset yang bernilai.

$$
\text { Menurut Paskard (1995), }
$$

Kepemimpinan adalah elemen kunci keberhasilan implementasi TQM. Pemimpin mempunyai perspektif 
jangka panjangdanharus mampu memotivasi bawahan. Hal tersebut diperlukan dalam menegakkan budaya oganisasi yang dilengkapi dengan TQM.

Hasil penelitian juga menolak
atau bertentangan dengan hasil
penelitian terdahulu yang telah
dilakukan oleh: Dayton (2003),
Baidoun(2003), Munizu (2003), dan
Metri (2005), dan menyimpulkan bahwa
komitmen atau dukungan manajemen
merupakan variabel yang berpengaruh
dominan terhadap keberhasilan
implementasi TQM.

Variabel pelatihan relatif lebih rendah $(4,02)$ dari pada nilai rata-rata tertinggi variabel: komitmen manajemen $(4,49)$, ternyata aktivitas pelatihan yang dilakukan oleh perusahaan lebih efektif memberikan kontribusi yang dominan dalam membentuk budaya kualitas jika dibandingkan dengan variabel-variabel implementasi TQM lainnya. Oleh karena itu, variabel pelatihan hendaknya dijadikan pertimbangan utama pihak manajemen dalam meningkatkan budaya kualitas.

\section{KESIMPULAN}

1. Terdapat pengaruhyang signifikan antara variabel-variabel dalam implementasi Total Quality Management yang terdiri dari: focus pada konsumen, perbaikan berkelanjutan, komitmen manajemen, pelatihan, pemberdayaan karyawan, perbandingan kinerja, dan penggunaan piranti statistik secara simultan terhadap budaya kualitas. Dengan demikian hipotesis pertama penelitian ini diterima.

2. Secara simultan variabel-variabel dalam implementasi Total Quality Management tersebut mampu menjelaskan pengaruhnya terhadap variabel budaya kualitas 63,5\%, sedangkan sisanya dijelaskan atau dipengaruhi oleh variabel bebas lain diluar persamaan model penelitian. Korelasi antara variabel-variabel dalam implementasi Total Quality Management terhadap budaya kualitas juga cukup kuat.

3. Terdapat pengaruh yang signifikan antara variabel dalam implementasi Total Quality Management yang terdiri dari: focus pada konsumen, komitmen manajemen, 
pelatihan,pemberdayaan

karyawan,dan penggunaan piranti statistic secara parsial terhadap variabel budaya kualitas, sedangkan variabel perbaikan berkelanjutan dan perbandingan kinerja tidak berpengaruh secara signifikan terhadap variabel budaya kualitas. Dengan demikian hipotesis kedua penelitian ini ditolak.

4. Variabel pelatihan mempunyai pengaruh yang dominan terhadap variabel budaya kualitas. Dengan demikian hipotesis ketiga penelitian ini ditolak.

\section{DAFTAR PUSTAKA}

Amar, Kiyafah \& Zuraidah Mohd Zain.(2001). Barriers in the Implementation of Total Quality Management in Indonesian Manufacturing Organizations. Jurnal Teknik Industri, Vol. 3, No. 2, Desember 2001

Dowling, P. \& Welch, D. E. (2004) International Human Resource Management: Managing People in a Multinational Context 4th edition, London UK, Thomson Learning.

Dowling, Peter J, Marion Festing and Allen D. Engle, 2008. International Human Resource Management: Managing People in a
Multinational Context : Fifth Edition, South- Western Cengage Learning, United Kingdom

Gaspersz, Vincent. 2001. Total Quality Management. Jakarta : Gramedia Pustaka Utama.

Handayani, 2005. Kaizen Culture, Education and Training, New York: Irwing Professional.

Hitoshi Takeda, 2006. The Change Management Handbook, New York: Irwing Professional.

Horngren, Charles T., George Foster., Srikant M. Datar. 2000. Cost Accounting: A Managerial Emphasis. International Edition.

Jurnal Akuntansi Vol.4 No.2 November 2012: 175-186. Pengaruh Penerapan Total Quality Management (TQM) dan Komitmen Organisasi terhadap Kinerja Perusahaan dengan Budaya Organisasi Sebagai Variabel Moderasi (Survei pada Perusahaan Manufaktur di Jawa Barat yang Listing di BEI)

Jurnal Akuntansi, Vol. 1, No. 2, April 2013 : 213-226. ISSN 2337-4314. Pengaruh Total Quality Management Terhadap Kinerja Financial (Study Pada Perusahaan Jasa di Kota Pekanbaru Provinsi Riau)

Krajewski, J. Lee and P. R. Larry, 2006, Operations Management Strategy and Analysis, Fifth Edition, Addison-Wesley Publising Company Inc.

Kujala, J., \& Lillrank, P. (2004). Total quality management as a cultural 
phenomenon. Quality Management Journal, 11(4), 43-55.

Prajogo, Daniel. I., and Brown, A. 2004. "The Relationship Between TQM Practice and Quality Performance and the Role of Formal TQM Programs: An Australian Empirical Study". Quality Management Journal. 11 (4), pp.31-42

Sisnuhadi. (2014). The Relationship between Soft Factors and Hard Factors of TQM Practices and Organizational Learning. European Scientific Journal, March 2014 edition, Vol. 10, No. 7.

The Influence of Total Quality Management (TQM) Applications to Sales Raising at PT. Kereta Api Indonesia (Persero) Bandung The 2nd Operations Area. ISBN: 978979-99365-7-8.

Kujala, J., \& Lillrank, P. (2004). Total quality management as a cultural phenomenon. Quality Management Journal, 11(4), 43-55.

Lincoln, J. R. (1989). Employee work attitudes and management practice in the US and Japan. California Management Review(Fall), 89-10. 